3. Bray. G. A.: A simple efficient liquid scintillator for counting aqueous solutions in a liquid scintillation counter. Anal. Biochem.. I: $279(1960)$.

4. Brothers, V.. Rowley, B. O.. and Gerritsen. T.: Oxidation of compounds metabolized through folate coenzyme pathways in vitamin $B_{12}$-deficient rats. Arch. Biochem. Biophss.. 166: 475 (1975).

5. Childs. B., Nyhan, W. L.. Borden, M.. Bard. L.. and Cooke. R. E.: Idiopathic hyperglycinemia and hyperglycinuria: a new disorder of amino acid metabolism. I. Pediatrics. 27: 522 (1961).

6. Davis. L.: A simple method for the synthesis of tetrahydrofolic acid. Anal. Biochem.. 26: 459 (1968)

7. Gerritsen. T., Kaveggia, E., and Waisman. H. A.: A new type of idiopathic hyperglycinemia with hypo-oxaluria. Pediatrics, 36: 882 (1965)

8. Giorgio, A. J.. and Plaut. G. W. E.: The effect of univalent cations on activities catalyzed by bovine-liver propionyl-CoA carboxylase. Biochim. Biophys. Acta, 139: 487 (1967)

9. Hillman. R. E.. Feigin. R. D., Tenenbaum, S. M.. and Kealting. J. P.: Defective isoleucine metabolism as a cause of the "ketotic hyperglycinemia" syndrome. Pediat Res. 6: 394 (1972)

10. Hillman, R. E., and Otto. E. F.: Inhibition of glycine-serine interconversion in cultured human tibroblists by products of isoleucine cataholism. Pediat. Res., 8: 941 (1974).

11. Hillman. R. E. Sowers, L. H., and Cohen, J. L.: Inhibition of glycine oxidation in cultured fibroblasts by isoleucine. Pediat. Res.. 7: 945 (1973).

12. Hommes, F. A., Kuipers, J. R. G., Elema, J. D., Jansen. J. F., and Jonxis, J. H. P.: Propionic acidemia, a new inborn error of metabolism. Pediat, Res.. 2: 519 (1968).

13. Hsia, Y. E.. Scully, K. J., and Rosenberg. L. E.: Inherited propionyl-CoA carboxylase deficiency in "ketotic hyperglycinemia." J. Clin. Invest.. 50: 127 (1971).

14. Jaffe, W. G., and Elvehjem. C. A.: Fractionation of growth-stimulating factor in liver. J. Biol. Chem., 169: 287 (1947).

15. Kosow. D. P.. and Lane, M. D.: Restoration of biotin-deficiency-induced depression of propionyl carboxylase activity in vivo and in vitro. Biochem. Biophys. Res. Commun.. 4: 92 (1961).

16. Lowry, O. H.. Rosebrough, N. J., Farr, A. L., and Randall, R. J.: Protein measurement with the Folin phenol reagent. J. Biol. Chem.. 193: 265 (1951).

17. Morrow, G. III, Barness, L. A.. Auerbach, V. H.. DiGeorge, A. M.. Ando. T. and Nyhan. W. L.: Observations on the coexistence of methylmalonic acidemia and glycinemia. J. Pediat., 74: 680 (1969).

18. Motokawa. Y., and Kikuchi. G.: Glycine metabolism in rat liver mitochondria. V. Intramitochondrial localization of the reversible glycine cleavage system and serine hydroxymethyltransferase. Arch. Biochem. Biophys.. 146: 461 (1971).

Copyright (c) 1975 International Pediatric Research Foundation. Inc
19. Oberhalzer V. G Levin B. Burgess, E A and Young. W. F: Methylmalonic aciduria- an inborn error of metabolism leading to chronic metabolic acidonis. Arch. Dis. Childhoud, 42: 492 (1967)

20. Reed. E. B.. and Tarver. H.: U rinars methylmalonic acid and hepatic melhylmalonyl-Cos mutase activity in the vitamin $\mathrm{B}_{12}$-deficient rat. I. Nutr., 100 935 (1970).

21. Rosenthal, S., Smith, L. C.. and Buchanan. 1. M.: En/miatic synthesis of the methyl group of methionine. J. Biol. Chem.. 240: 836 (196.5)

22. Rubin, S H Drekter L and Mover, F. HI: Biological activits of sunthetic d.I-desthiobiotin. Proc. Soc. Exp. Biol. Med., 58: 352 (1945).

23. Schnatman. C., and Greenawalt, J. W.: Ensmatic properties of the inner and outer membranes of rat liver mitochondria. J. Cell Biol., 38: 158 (1968).

24. Spackman, D. H. Stein. W. H. and Moore. S.: Automatic recording apparatus for use in the chromatography of amino acids. Anal. Chem., 30:1190 (1958).

25. Tada, K., Corbeel, L. M.. Eeckels, R., and Eggermont. E.: A block in glycine cleavage reaction as a common mechanism in ketotic and non-ketotic hyperglycinemiat. Pediat. Res.. 8: 721 (1974).

26. Tada, K., Narisauat. K.. Yoshida. T.. Konno. T., Yokoyama, Y.. Nakagawa, H.. Tanno. K.. Mochizuki. K.. Arakawa, T., Yoshida. T.. and Kikuchi, G.: Hyperglycinemia: A defect in glycine cleavige reaction. Tohoku J. Exp. Med., 98: $289(1969)$.

27. Taylor, R. T., and Weissbach, H.: Radioactive assay for serine transhydroxymethylase. Anal. Biochem.. 13: 80 (1965)

28. Yoshida, T., and Kikuchi. G.: Major pathwass of glveine and serine catabolism in rat liver. Arch. Biochem. Biophys. 139: 380 (1970).

29. Boston. Mass

30. Arlington Heights, $\mathrm{Va}$

31. Cleveland, Ohio.

32. Los Angeles. Calif.

33. St. Louis, Mo.

34. Rochester, N. Y

35. Division of ARS/Sprague-Dawley, Madison, Wisc.

36. Holzman Co. Madison, Wise.

37. Kontes Glass Co.. Vineland, N. J.

38. The authors thank Dr. James Bloomer for use of the apparatus for the respiration pattern experiments and Alan Hamstra for the amino acid analyses.

39. This study was made possible by Training Grant HD0013/ from the National Institutes of Health.

40. Requests for reprints should be addressed to: T. Gerritsen. D.Sc.. Professor of Pediatrics and Physiological Chemistry, University of Wisconsin, 613 Waisman Center. 2605 Marsh Lane. Madison. Wisc. 53706 (USA)

41. Accepted for publication June 25. 1975.
Esterification oleic acid lipids

\title{
Uptake, Activation, and Esterification of Fatty Acids in the Small Intestine of the Suckling Rat
}

\author{
PHILIP G. HOLTZAPPLE (46' GLEN SMITH, AND OTAKAR KOLDOVSKÝ
}

Department of Pediatrics, University of Pennsylvania School of Medicine. Children's Hospital of Philadelphia.

Philadelphia, Pennsilvania. U'SA

\section{Extract}

The small intestinal mucosal phase of fatty acid absorption was studied in suckling and adult rats. Fatty acid binding protein (FABP) is present in the cytosol of jejunal mucosa of 6-day-old rats in amounts equivalent to that found in mucosal cytosol of adult rats ( $16.4 \%$ and $15.0 \%$, respectively). The percentage of oleic acid binding to FABP is the same in 6-day-old and adult rats $113.9 \%$ and $10.2 \%$, respectively). The specific activity of jejunal microsomal oleovl-CoA synthetase is high in the fetus, falls abruptly after birth, but increased by the third day of life to remain constant thereafter into adult life. In contrast the specific activity of acylCoA:monoglyceride acyltransferase is low in the fetal jejunum, grad- ually increases, and is significantly higher in the 6- and 12-day-old rat than in the adult. Uptake of oleic acid by jejunal slices of 6and 11-day-old animals is three- to fivefold higher than uptake by jejunal slices prepared from adults rats. The rate of esterification of oleic acid is higher in jejunal slices from 6- and 11-day-old rats, reflecting the enhanced uptake of oleic acid.

\section{Speculation}

In the suckling rat, the increased intestinal mucosal epithelial cell capacity for fatty acid esterification coincides with a diminished lipolytic activity within the lumen. This paradox suggests that the fatty acid esterification process in the small intestine of the suckling 
rat may be involved with aspects of lipid metabolism other than that of fatty acid absorption. Extrapolating these observations on experimental animals to the human neonate, we suggest as working hypothesis that inefficient fat absorption should not be attributed to diminished mucosal epithelial cell function.

Extensive studies, especially in the last decade, have delineated the mechanisms for fat absorption in adult mammals, including man. In comparison our knowledge of these same processes during the early perinatal period is relatively meager. A more complete understanding of the mechanism of fat absorption in the newborn is needed as fat is an important nutrient during this particular period of life. The high fat content of natural milk and commercially prepared formulas subjects the human infant to an ingested fat load which exceeds that encountered by the mature individual.

Balance studies, performed in infants during the first 3 months of life, show a lower coefficient of fat absorption, especially in those infants on cow milk-based formulas $(1,8,10,32,37,39)$. Many factors may contribute to the relative inefficiency of absorption of lipid by the newborn. It has been shown recently that the pool size of conjugated bile acids is smailer in infants than in adults (36), and is further diminished in low birth weight infants (35). However, the balance studies performed on newborns have repeatedly been interpreted as indicating the existence of diminished lipolytic activity in the gastrointestinal contents of young infants $(8,10,34,37)$. Recent studies by Zoppi and coworkers (38) have firmly established the validity of this observation by measuring pancreatic lipase output after intravenous pancreozyminsecretin stimulation. In addition to these studies on human infants, previous studies in animals have shown that low lipolytic activity of gastrointestinal secretions is a general phenomenon and not limited to the human infant $(4,5,13,14,26,30)$. Thus, although the clinical and animal studies have concentrated on the luminal phase of fat absorption, the mucosal phase has been practically neglected. In the studies presented in this report, we evaluated the mucosal phase of lipid absorption during the perinatal period. The suckling rat was chosen for several reasons. Suitable data of fat digestion and absorption have been accumulated from the studies with the adult rat, and both man and rat are known to have a low lipase activity during the immediate period after birth. In addition, the rat is born relatively immature and offers the opportunity to study the processes of lipid digestion and absorption during the different phases of perinatal development.

The mucosal phase of fat absorption was evaluated during the perinatal period by studying both the activity of the microsomal enzymes involved in the esterification of free fatty acids and the esterification capacity of the total intestinal tissue. Studies also included the evaluation of FABP in suckling and adult rats. Preliminary reports were presented elsewhere $(7,43)$.

\section{MATERIALS AND METHODS}

Pregnant Charles River females shipped as 12-day pregnant animals gave birth in our own animal house. The litter size was reduced to 8-9 animals at the third day after birth. Suckling rats were taken directly from the mother and killed by decapitation at 9 AM. Microsomes were prepared from the jejunum (first third of the small intestine) and the ileum (last third of the small intestine) according to the methods described by Rodgers, et al. (28). The entire intestinal wall of rat fetuses, 1- and 3-day-old rats was used at the initial starting tissue for microsomal preparations. In older rats, mucosal scrapings were obtained and used as the initial starting material. The specimens from one litter were pooled and treated as one sample; small intestine from fed 3-month-old male rats was used singularly as samples of adult intestine. Contamination by other cell fractions was evaluated by the appropriate enzymatic and biochemical markers: the presence of microvilli was monitored by assay for neutral $\beta$-galactosidase (15), lysosomes by acid $\beta$-galactosidase (15), mitochondria by succinodehydrogenase
(24), and nuclei by DNA (11). Protein was determined by the Folin-phenol reaction (19).

The determination of oleoyl-CoA synthetase activity was based on the hydroxamic acid trapping method of Kornberg and Pricer (18), as modified for the small intestine by Rodgers et al. (29). Oleic acid was homogenized in $0.27 \%$ lecithin so that the final concentrations of oleic acid and lecithin were 1.95 and $8.5 \mathrm{mM}$ respectively. Acyl-CoA:monoglyceride acyltransferase (EC. 2.3.1) was assayed as described previously (7) according to the method of Rodgers (27), using palmitoyl-CoA and 1 -mono-olein as substrates at final concentrations of 0.17 and $0.09 \mathrm{mM}$ respectively. The sulfhydryl trapping agent, 5,5'-dithiobis-(2nitrobenzoic acid) was used to measure the rate of $\mathrm{CoA}$ liberated by the reaction. The activity of both enzymes was assayed under linear conditions with respect to time and protein concentration. Under standard conditions $0.1 \mathrm{mg}$ microsomal protein was used for both assays.

Uptake and esterification of fatty acid were studied in vitro using jejunal slices according to the method described by Clark (2). Three slices of jejunal mucosa, weighing between 10 and $20 \mathrm{mg}$ each from either 6-day-old, 11-day-old, or adult rats were incubated in flasks containing $2 \mathrm{ml}$ Krebs-Ringer phosphate buffer $(\mathrm{pH}$ 7.4) without added calcium or magnesium. containing $1 \mathrm{mM}$ $\left[1-{ }^{4} \mathrm{C}\right.$ ]oleic acid (specific activity $\left.0.3 \mu \mathrm{Ci} / \mathrm{mM}\right)(40)$ and $10 \mathrm{mM}$ sodium taurocholate (41). After $15 \mathrm{~min}$ of preincubation at $0.52^{\circ}$ (cold), the flasks were transferred to $37^{\circ}$ water bath for given periods of time. Slices were then removed, rinsed twice in nonradioactive media, blotted on a moist filter paper, weighed, and plunged into test tubes containing $1 \mathrm{ml} 0.1 \mathrm{~N} \mathrm{HCl}$. Lipids were extratcted from the homogenized slices by standard methods (9) and separated by Silica Gel G (42) thin layer chromatography. The areas corresponding to the mono, di-, and triglycerides and fatty acid standards were scraped into the scintillation vials containing $10 \mathrm{ml}$ toluene containing 3\% Liquiflor $(40)$ and the radioactivity counted at $85 \%$ efficiency. Using the external standarization methods, there was no significant quenching of any of the samples analyzed.

The FABP in jejunal mucosal cytosol was determined according to the method of Ockner et al. (22). [ $\left[-^{14} \mathrm{C}\right]$ Oleic acid $(220 \mu \mathrm{mol})$ (40) was added to $30.40 \mathrm{mg}$ cytosol protein, incubated on ice for $30 \mathrm{~min}$ with intermittent mixing, applied to a Sephadex G-75 column, and eluted in 4-ml fractions. Fractions 24-28 contained FABP and were assayed for protein and radioactivity.

\section{RESULTS}

To evaluate the esterification capacity of the small intestine during the perinatal development two approaches were chosen. The first one involved determination of the activity of the two microsomal enzymes involved in the esterification pathway. These studies using isolated microsomes were paralleled by a second group of experiments in which the esterification capacity of the small intestine was evaluated by studying the uptake and esterification of fatty acids by intestinal slices incubated in vitro.

PERINATAL CHANGES OF ACTIVITY OF OLEOYL-COA SYNTHETASE AND ACYL-COA: MONOGLYCERIDE/ACYLTRANSFERASE IN JEJUNAL AND ILEAL MUCOSA

Activity of these enzymes was determined in isolated microsomal fractions of intestinal mucosa. Before the developmental studies were started, we evaluated the quality of the isolated microsomal fraction obtained from small intestinal mucosa of rats of various ages. As seen in Table 1, the recovery of protein in the microsomal fraction from mucosa of rats of all ages is fairly similar. DNA and succinodehydrogenase activity was present, in the microsomal fractions in all age groups, but the amount was always less than $0.5 \%$ of the amount in the initial homogenate. The contamination by microvilli as judged by the amount of neutral $\beta$-galactosidase activity in the microsomal fraction never exceeded 
Table 1. Comparison of microsomal preparations from jejunum and ileum of developing rats

\begin{tabular}{|c|c|c|c|c|}
\hline & & Protein ${ }^{1}$ & $\begin{array}{c}\text { Neutral } \beta \text {-galac- } \\
\text { tosidase }^{1}\end{array}$ & $\begin{array}{c}\text { Acid } \beta \text {-galac- } \\
\text { tosidase }\end{array}$ \\
\hline \multirow[t]{2}{*}{ Fetus } & Jejunum & $9.5 \pm 2.7(3)^{2}$ & $8.4 \pm 5.5(3)$ & $2.1 \pm 0.5(3)$ \\
\hline & Ileum & $8.0 \pm 2.0(3)$ & $7.6 \pm 2.3(3)$ & $3.8 \pm 0.1(3)$ \\
\hline \multirow[t]{2}{*}{ 3-day-old } & Jejunum & $6.8(1)$ & $10.7 \pm 2.3(3)$ & $2.3 \pm 0.5(3)$ \\
\hline & Ileum & $4.1 \pm 0.5(3)$ & $11.6 \pm 3.5(3)$ & $8.1 \pm 2.6(3)$ \\
\hline \multirow[t]{2}{*}{ 6-day-old } & Jejunum & $7.0 \pm 1.8(4)$ & $9.9 \pm 1.2(4)$ & $5.7 \pm 2.1(4)$ \\
\hline & Ileum & $4.4 \pm 0.4(4)$ & $9.0 \pm 4.0(3)$ & $6.6 \pm 2.9(3)$ \\
\hline \multirow{2}{*}{ 12-day-old } & Jejunum & $7.0 \pm 1.9(4)$ & $12.1 \pm 2.7(3)$ & $7.6 \pm 1.4(6)$ \\
\hline & Ileum & $4.8 \pm 0.7(6)$ & $16.9 \pm 2.5(3)$ & $10.0 \pm 1.7(6)$ \\
\hline \multirow[t]{2}{*}{ Adult } & Jejunum & $7.5 \pm 0.6(13)$ & $12.3 \pm 2.8(12)$ & $5.9 \pm 1.1(13)$ \\
\hline & Ileum & $6.6 \pm 0.5(11)$ & $11.2 \pm 2.3(10)$ & $8.7 \pm 2.3(11)$ \\
\hline
\end{tabular}

${ }^{1}$ Percentage of amount present in total homogenate.

${ }^{2}$ Mean \pm SE (number of determinations).

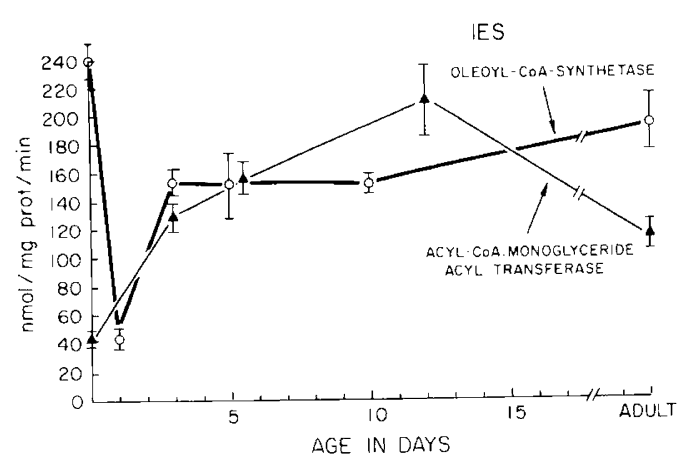

Fig. 1. Developmental pattern of microsomal oleoyl-CoA synthetase and acyl CoA:monoglyceride acyltransferase activity in rat jejunum. Results are expressed as nanomoles of product formed per mg of protein per min. Each point represents the mean $\pm \mathrm{SE}$ of at least four litters for the suckling rats and 13 adult animals. There is no difference in oleoyl-CoA synthetase activity among 3-, 5-, 10-day-old, and adult values. Fetal and adult values of acyltransferase activity are significantly lower than the values of either the 6 - or the 12-day-old animals $(P<0.01)$.

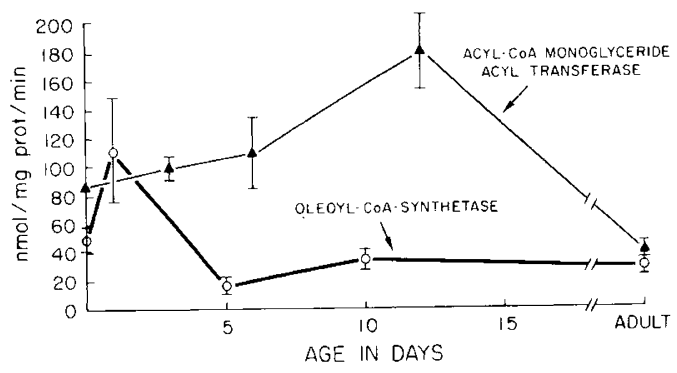

Fig. 2. Developmental pattern of microsomal oleoyl-CoA synthetase and acyl-CoA:monoglyceride acyltransferase activity in rat ileum. Results are expressed as in Figure 1. There is no difference in oleoyl-CoA synthetase activity among the 5-, 10-day-old, or adult values. Acyltransferase activity in the adult is significantly lower than in the 6-day-old $(P<0.05)$ and in the 12-day-old animal $(P<0.001)$.

$17 \%$ of the total homogenate and is similar to that reported by others for microsomes prepared from the mucosa of adult rats ( 3 , 12 ). The amount of acid $\beta$-galactosidase acitivity varied in jejunal preparations from 2 to $8 \%$, in ileal preparations from 4 to $10 \%$ of the total homogenate activity. As these microsomal preparations were judged to be satisfactory for further experiments, perinatal changes of the above mentioned microsomal enzymes were followed in the jejunum and ileum separately.

Jejunum. The highest activity of oleoyl-CoA synthetase was found in rat fetal jejunum. The activity falls rapidly after birth, but rises again sharply by the third day of life to remain constant thereafter into adult life (Fig. 1). With the exception of the change in activity during the first 2 days of life, the activity of this enzyme in jejunal microsomes does not differ during the suckling period from that found in the intestinal mucosal microsomes prepared from adults rats. The activity of acyl-CoA monoglyceride acyltransferase is low in the rat fetus, gradually increases, and is highest in 6- and 12-day-old rats. These values are significantly higher than those found in microsomes prepared from either fetal or adult intestine.

Ileum. Changes of activity of these enzymes in the ileum are depicted in Figure 2. In contrast to the high specific activity of oleoyl-CoA synthetase in the jejunum, low values were found in microsomes from the ileum of the fetal rat. This activity remains low thereafter into adult life. A proximal-distal gradient of synthetase activity exists during the fetal life, and changes little throughout the life of a rat. The activity of acyl-CoA:monoglyceride acyltransferase in the ileum follows a pattern similar to that seen in the jejunum. The specific activity increases slowly from fetal values to a peak by 12 days of age. Thereafter a gradual decrease in activities is seen. A proximal-distal gradient of acyltransferase activity is not observed in the perinatal period; a gradient in adult rats is observed as reported by Rodgers et al. (28, 29).

RATE OF UPTAKE AND ESTERIFICATION OF OLEIC ACID BY INTESTINAL SLICES FROM SUCKLING AND ADULT RATS

In these experiments, the esterification capacity was evaluated using intact intestinal slices. Based upon the previous experiments we have limited the experiments to the jejunum and have used only 6- or 11-day-old suckling rats and adults. Since during the esterification process at least two steps are involved, namely, uptake and esterification, the first experiments were designed to evaluate uptake alone.

Uptake. Uptake was studied at $0.5-2^{\circ}$ (cold) since esterification was found to be inhibited at this temperature (20). In agreement with this observation, we have found that esterified fatty acids accounted for less than $10 \%$ for the total tissue radioactivity at all periods of incubation studied. A faster rate of oleic acid uptake was observed in jejunal slices obtained from the suckling rats than from adult rats (Fig. 3).

Esterification. In the next set of experiments the esterification rate of the accumulated oleic acid was studied. After $15 \mathrm{~min}$ of incubation in the cold, the flasks were transferred to a $37^{\circ}$ water bath for varying periods of incubation. The results of these studies are depicted in Figure 4. Esterification is expressed as nanomoles of oleic acid converted to triglyceride. In all of these experiments, esterified oleic acid, either as monoglyceride or diglyceride, accounted for less than $5 \%$ of the total esterified oleic acid. As shown, the oleic acid is esterified to triglycerides at faster rates in jejunal slices from the suckling rats than in slices from adult rats. 


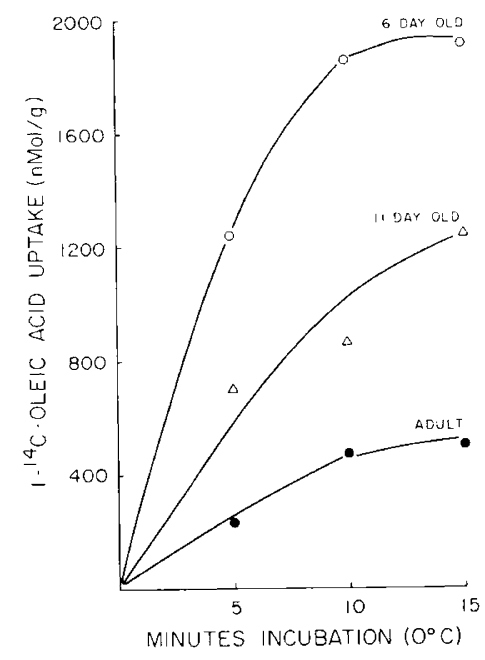

Fig. 3. Uptake of $\left[1-{ }^{14} \mathrm{C}\right]$ oleic acid by jejunal slices from 6-, 11-dayold, and adult rats. Incubations were performed in triplicate; two litters of each age group and three adults were studied. The symbols represent the mean value of all flasks for each time point. Results are expressed as nanomoles of oleic acid per $g$ of wet tissue weight.

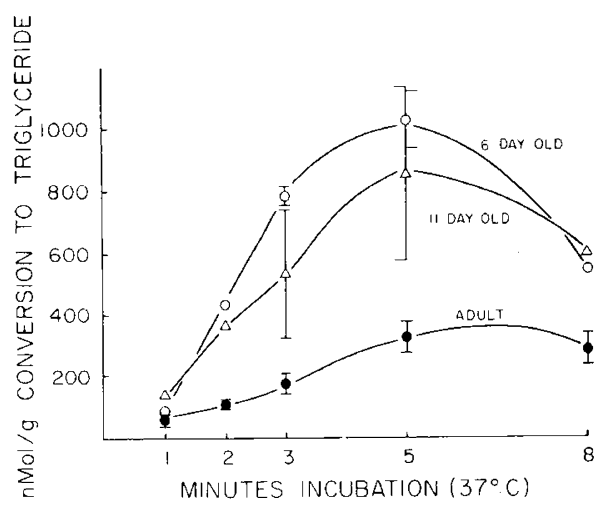

Fig. 4. Esterification of $\left[1-{ }^{14} \mathrm{C}\right]$ oleic acid by jejunal slices from suckling and aduit rats. Each point represents the mean \pm SE of four litters of suckling or seven adult rats; each time point for each experiment was performed in triplicate. Results are expressed as nanomoles of oleic acid converted to triglyceride per $\mathrm{g}$ of wet tissue weight.

When the ratio of esterified fatty acid after incubation at $37^{\circ}$ to free fatty acid present at the end of the incubation in the cold is calculated, no difference between the three age groups is seen (Fig. 5). Therefore, the higher rate of esterification in suckling rats appears to be directly proportional to the higher rate of uptake of oleic acid during the cold preincubation.

Among the various possibilities explaining the higher uptake of oleic acid of suckling rat slices, we have considered the role of FABP. known to be present in adult rat mucosa and found to be increased in the adult rat by high fat diet (23). Fatty acid binding protein is present in cytosol of jejunal mucosa from 6-day-old rats. Neither the amount of FABP nor the percentage of oleic acid binding in a 6-day-old rat jejunal mucosal cytosol is different from that found in adult rat (Table 2). It appears as though an additional factor other than the function of FABP accounts for the increased uptake of oleic acid in jejunal slices from suckling rats.

\section{DISCUSSION}

There are two aspects of our present work that we want to discuss. As we have studied the activity of two of the three enzymes which constitute the triglyceride synthetase complex and the esterification capacity of the entire slice, the first aspect deals with the discrepancy of the rate of these reactions as disclosed in our experiments. The second aspect is concerned with the functional projections of our data for the more general problem of lipid digestion and absorption by the gastrointestinal tract during the early postnatal period in mammals, including man.

The process of triglyceride absorption is divided customarily into three main phases: luminal, mucosal, and transport phases. We have, in this series of experiments, studied several aspects of the mucosal phase. The esterification capacity of the small intestinal mucosa was evaluated both by studying the activity of two microsomal enzymes as well as by determination of the capability of the entire intestinal slice in vitro to convert oleic acid to triglyceride. Although the determination of enzyme activity showed only minor differences between adult and suckling rats (in favor of the latter), the rate of esterification by the jejunal slices in vitro from suckling rats exceeded by several times the rate found in preparations from adults. This difference, as judged from the data derived from the two different types of experiments, can be interpreted as indicating that the activity of the enzymes is not the limiting factor, but that the process of esterification is regulated by other factors as well. We are aware that the present data, obtained under in vitro conditions, are limited by this experimental approach and have to be extended by future experiments in vivo; however, we can conclude that the availability of free fatty acid on, or in, the intestinal tissue is one factor responsible for the increased rate of esterification. This conclusion is based on the close correlation between the rate of oleic acid uptake and esterification rate in different age groups. The reason for the higher uptake in suckling rats remains obscure: data from the FABP experiments suggests that the amount of FABP does not cause this difference. Recent data of Marrubio et al. (20) offer another explanation for this observation. These authors found that intestinal slices from

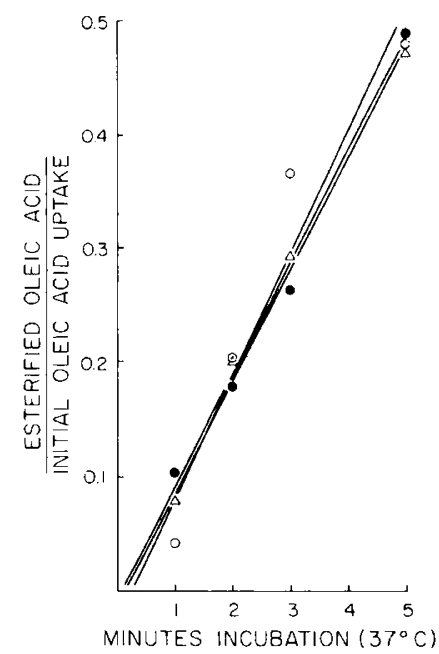

Fig. 5. Ratio of esterified oleic acid to initial oleic acid taken up by jejunal slices preincubated in the cold for $15 \mathrm{~min}$ in 6-day-old $(O)$. 11-dayold $(\Delta)$, and adult rats $(\bullet)$

Table 2. Fatty acid binding protein in jejunal mucosa of suckling rats

\begin{tabular}{lcc}
\hline & \% Total protein & $\begin{array}{c}\text { \% Oleic acid } \\
\text { binding }\end{array}$ \\
\hline 6-day-old & $16.4 \pm 0.9(4)$ & $13.9 \pm 4.0$ \\
Adult & $15.0 \pm 2.1(5)$ & $10.2 \pm 1.0$ \\
\hline
\end{tabular}

' Expressed as percentage of total supernate protein: number of animals in parentheses.

${ }^{2}$ Expressed as percentage of total amount of $\left[{ }^{14} \mathrm{C}\right]$ oleic acid added to cytoplasmic supernate. 
adults, if preloaded in vitro with monoglyceride, accumulated fatty acids at a faster rate than control slices. Thus we can speculate about the possible effect of an increased tissue pool of monoglyceride in the intestine of suckling rats. Both the verification of a similar mechanism in suckling rats as well as its manifestation after peroral intake remain to be shown.

Although the data from the experiments delineating the developmental pattern of the activity of the microsomal enzymes show little difference between the suckling and adult rat, another aspect is interesting. As individual separation of the enzymes comprising the triglyceride synthetase complex has not been achieved (25), the finding of nonparallel behavior of oleoyl-CoA synthetase and monoglyceride acyltransferase activity during development (high synthetase and low acyltransferase activity in the fetus) raises some questions concerning the metabolic regulation of this complex. Whereas McManus and Isselbacher (21) have shown an increase in palmitoyl-CoA synthetase activity in microsomes of adult rats fed a high fat diet and a decrease in rats on a fat-free diet, our findings of high fetal activity and the absence of a decrease after the weaning when the fat intake falls suggest that regulation acyl-CoA synthetase activity in the suckling rat may not reflect the influence of the exogenous fat load as much as in the adult. Other factors during the suckling period, such as hormonal factors, may be more influential than the effect of the dietary load. Further studies are underway exploring these possibilities. Another consideration is that our data were obtained using oleic acid. Although the amount of oleic acid in milk is substantial, both human and rat milk contain a relatively large amount of medium chain length fatty acids $(6,16,17)$. Thus it is obvious that corresponding studies in which these shorter chain fatty acids are used as substrates in experiments with suckling animals are needed.

The second aspect of these studies centers around the general picture of lipid digestion and absorption in suckling animals and whether it differs substantially from that in the adult animal. Before our present data were obtained a paradoxic situation existed: fat intake is high in the suckling animal when the lipolytic activity of the gastrointestinal tract is low $(16,17)$. With our data we can extend this paradox by comparing the low lipolytic activity with the higher rate of esterification within the epithelial cell. There are several possible explanations for this second paradox. In sucklings the high re-esterification rate is only a reflection of the high uptake of fatty acids. This high uptake (if proven in vivo) is logical in the light of the high fat intake. A similar relationship has been shown in adult rats placed on a high fat diet (31). The question to be answered is whether the high uptake of fatty acids is paralleled also by a high uptake of all lipid components. If this observation is proven then the low lipolytic activity accompanied by high uptake of all the forms of luminal lipid would suggest that the gastrointestinal tract of the suckling rat is capable of handling lipid in a manner analogous to the manner in which it handles other macromolecules such as proteins during this stage of life (33). Another possibility to explain the high esterification of absorbed free fatty acids may be more involved in the transesterification of glycerides, especially those from the circulation. This would place the gastrointestinal tract of the suckling animal in a more significant and central role in the regulation of lipid metabolism of the organism as a whole.

\section{SUMMARY}

Several processes of the mucosal phase of fatty acid absorption from the small intestine of the suckling rat were compared with those of the adult rat. In vitro studies showed that the uptake of oleic acid by jejunal slices from suckling rats is three- to fivefold greater than is observed from adult rats. The rate of esterification of oleic acid was correspondingly higher. The activity of acylCoA:monoglyceride acyltransferase in isolated mucosal microsomes is higher (about $50 \%$ ) in microsomes prepared from the jejunum of suckling rats than of the adult rat. The activity of
oleoyl-CoA synthetase is similar to that found in adults. The amount of fatty acid binding protein and the percentage of oleic acid binding is similar in intestinal cytosol of 6-day-old and adult rats.

\section{REFERENCES AND NOTES}

1. Barltrop. D.. and Oppé, T. E.: Absorption of fat and calcium by low birth weight infants from milks containing butterfat and olive oil. Arch. Dis. Childhood, 48 . 491 (1973).

2. Clark, S. B.: The uptake of oleic acid by rat small intestine: A comparison of methodologies. J. Lipid Res., 12: 43 (1971).

3. Clark, M. L., Lanz, H. C., and Senior, J. R.: Enzymatic distinction of rat intestinal cell brush border and endoplasmic reticular membranes. Biochim. Biophys. Acta, /83: 2331969.

4. Corring, T, and Aumaitre, A.: Mise en place et évolution de l'équipment enzymatique du pancreas exocrine du jeaune rat pendant la période embryonnaire, L'allaitement et le sebrage. Ann. Biol. Anim. Biochem. Biophys.. 10: 431 (1970).

5. Delachaume-Salem, E., and Sarles, H.: Normal human pancreatic secretion in relation to age. Biol. Gastroenterol. 2: 135 (1970).

6. Dobiášová, M., Hahn, P., Koldovský, O.: Fatty acid composition in developing rats. Biochim. Biophys. Acta, 84: 538 (1964).

7. Eisen, A., Holtzapple, P., and Koldovský, O.: Perinatal changes of the activity of acyl-CoA:Monoglyceride acyltransferase in the rat intestinal mucosa. Experientia, 29: 405 (1973).

8. Filer, L. J., Mattson F. H., and Fomon, S. J.: Triglyceride configuration and fat absorption by the human infant. J. Nutr., 99: 29 (1969).

9. Folch. J.. Lees, M., and Sloane Stanley, G.: A simple method for the isolation and purification of total lipids from animal tissues. J. Biol. Chem., 226: 497 (1957).

10. Fomon, S. J., Ziegler, E. E., Thomas, L. N., Jensen, R. L.. and Filer, L. J.. Excretion of fat by normal full term infants fed various milks and formulas. Amer. J. Clin. Nutr., 23: 1299 (1970).

11. Giles, K. W., and Myers, A.: An improved diphenylamine method for the estimation of DNA. Nature, 206: 93 (1965).

12. Grand. R. J.. Chong, D. A., and Isselbacher, K.: Intracellular processing of disaccharides: The effect of actinomycin D. Biochim. Biophys. Acta, 261:341 (1972).

13. Hadorn. B., Zoppi, G., Schmerling, D. H., Prader, A., Mclntyre, I., and Anderson, C. M.: Quantitative assessment of exocrine pancreatic function in infants and children. J. Pediat., 73: 39 (1968).

14. Hamosh. M., and Scow, K. O.: Lingual lipase and its role in the digestion of dietary lipids. J. Clin. Invest., 52: 88 (1973).

15. Koldovsky, O., Asp. N. G., and Dahlquist, A.: A method for the separate assay of "neutral" and "acid" $\beta$-galactosidase in homogenates of rat small-intestine mucosa. Anal. Biochem. 27: 409 (1969).

16. Koldovský, O.: Hormonal and dietary factors in the development of digestion and absorption. In: M. Winick: Nutrition and Development. p. 135 ed. (J. Wiley \& Sons. New York, 1972)

17. Koldovsky, O.: Development of the Functions of the Small Intestine in Mammals and Man, p. 9! (Karger, Basel, 1969).

18. Kornberg, A.. and Pricer, J. W. E.: Enzymatic synthesis of the coenzyme. A. derivative of long chain fatty acids. J. Biol. Chem. 204: 329 (1953).

19. Lowry, O. H., Rosebrough, N. J., Farr, A. L., and Randall, R. J.: Protein measurement with the Folin phenol reagent. J. Biol. Chem. 193: 265 (1951).

20. Marrubio, A. T., Jr., Morris, J. A., Jr., Clark, S. B., and Holt, P. R. Monoglyceride modification of jejunal absorption of fatly acid in the rat. J. Lipid Res., 15: 165 (1974).

21. McManus, J. P. A., and Isselbacher, K. J.: Effect of fasting versus feeding on the rat small intestine: Morphological, biochemical and functional differences. Gastroenterology, 59: 214 (1969).

22. Ockner, R. K., Manning, J. A., Poppenhausen, R. B., and Ho, W. K. L.: A binding protein for fatty acids in cytosol of intestinal mucosa, liver, myocardium and other tissues. Science, 17756 (1972).

23. Ockner, R. K., and Manning, J. A.: Fatty acid binding protein in small intestine: Identification, isolation, and evidence for its role in cellular fatty acid transport. J. Clin. Invest., 54: 326 (1974)

24. Pennington, R. J.: Biochemistry of dystrophic muscle: Mitochondrial succinatetetrazolium reductase and adenosine triphosphate. Biochem. J., 80:649 (1961).

25. Rao, G. N., and Johnson, F. M.: Purification and properties of triglyceride synthetase from the intestinal mucosa. Biochim. Biophys. Acta, 125: 465 (1966).

26. Robberecht, P., Deschodt-Lanckman, M., Camus, J., Bruylands, J., and Christophe, J.: Rat pancreatic hydrolases from birth to weaning and dietary adaptation after weaning. Amer. J. Physiol., 221: 376 (1971)

27. Rodgers, J. B.: Assay of acyl-CoA: Monoglyceride acyltransferase from rat small intestine using continuous recording spectrophotometry. J. Lipid Res., 10: 427 (1969).

28. Rodgers, J. B., Riley, E. M. Drummey, G. D., and Isselbacher, K. J.: Lipid absorption in adrenalectomized rats: The role of altered enzyme activity in the intestinal mucosa. Gastroenterology, 53: 547 (1967).

29. Rodgers, J. B., Tandon, R., and Fromm, H.: Acyl-CoA synthetase for long chain fatty acids in rat small bowel and the influence of diets containing different compositions of fatty acids on intestinal lipid re-esterifying enzyme activities. Biochim. Biophys. Acta, 270: 453 (1972). 
30. Rokos, J. Hahn, P., Koldovsky, O., and Procházka, P.: The postnatal development of lipolytic activity in the pancreas and small intestine of the rat. Physiol. Bohemoslov, 12: 213 (1963)

31. Singh, A., Balint, J. H., Edmonds, R. H., and Rodgers, J. B.: Adaptive changes of the rat small intestine in response to a high fat diet. Biochim. Biophys. Acta, 260: 708 (1972).

32. Tomarelli, R. M.. Meyer. B. J.. Weaber, J. R., and Bernhard, F. W.: Effect of positional distribution on the absorption of the fatty acids of human milk and infant formulas. J. Nutr., 95: 583 (1968).

33. Walker, W. A., and Isselbacher, K. J.: Uptake and transport of macromolecules by the intestine: Possible role in clinical disorder. Gastroenterology. 67: 531 (1974).

34. Watkins, J. B., Bliss, C. M.. Donaldson, R. M., and Lester, R.: Characterization of newborn fecal lipid. Pediatrics, 53: 511 (1974).

35. Watkins, J. B. Szcepanik, P., Gould, J., Klein, P. D., and Lester, R.: Bile salt kinetics in premature infants: An explanation for inefficient lipid absorption. Gastroenterology, 64: 817 (1973).

36. Watkins, M. B., Ingall, D., Szczepanik, P., Klein, P. D., and Lester, R.: Bile salt metabolism in the newborn. New Eng. J. Med., 288: 43 ! (1973).

37. Widdowson. E. M.: Absorption and excretion of fat, nitrogen and minerals from "filled" milks by babies one week old. Lancet, ii: 1099 (1965).

38. Zoppi, G Andreotli, G Pajno-Ferrara, F Njai, D M and Gaburro, D Exocrine pancreas function in premature and full term neontates. Pediat. Res. 6: 880 (1972)

39. Zoula, J., Melichar. V., Novák. M., Hahn, P., and Koldovský. O.: Nitrogen and fat retention in premature infants fed breast milk "humanized" cow's milk of half skimmed cow's milk. Acta. Pediat. Scand. 55: 26 (1966).

40. New England Nuclear, Inc., Boston, Mass.

41. Calibiochem, Los Angeles, Calif.

42. Brinkman Instruments, Inc., Westbury, N. Y

43. Presented in part at the Society for Pediatric Research Meeting, Washington, D. C. (Pediat. Res., 8: 83 (1974))

44. This research was supported in part by Grant 14531 from the National Institutes of Health.

45. Dr. P. G. Holtzapple is recipient of Research Career Development Award No. I-K4-HD-70026 from the National Institutes of Health.

46. Requests for reprints should be addressed to: P. G. Holtzapple. M.D. The Children's Hospital of Philadelphia, One Chidren's Center, 34th \& Civic Center Blvd., Philadelphia, Pa. 19104 (USA)

47. Accepted for publication June 25, 1975.

\title{
Bilirubin Interaction with Ganglioside: Possible Mechanism in Kernicterus
}

\author{
MARVIN L. WEIL ${ }^{(25)}$ AND JOHN H. MENKES
}

Department of Pediatrics and Neurology. Harbor General Hospital Campus, UCLA School of Medicine and

Brentwood Veterans Administration Hospital, UCLA School of Medicine, Los Angeles, California, USA

\section{Extract}

Reaction of bilirubin with increasing amounts of ganglioside purified from neonatal brain significantly alters the spectral absorption of bilirubin in proportion to the quantity of ganglioside added. Increments in absorbance occur at $353 \mathrm{~nm}$ with a prompt but transient increase at $486 \mathrm{~nm}$. A decrease in absorbance occurs which is most marked at $447 \mathrm{~nm}$. When gangliosides are added to bilirubin $(9.1 \mu \mathrm{g} / \mathrm{ml}$ or $0.016 \mu \mathrm{M} / \mathrm{ml})$, the decrease in absorbance is essentially linear up to the highest concentration of purified ganglioside tested $(182 \mu \mathrm{g} / \mathrm{ml}$ or $0.097 \mu \mathrm{M} / \mathrm{ml}$ ), which represents a molar ratio of $6.1: 1$. The asymptotic nature of the bilirubin-ganglioside reaction as measured by the decrease in absorbance with time suggests a stoichiometric relationship between the two substances. An isosbestic point was demonstrated at $405 \mathrm{~nm}$. Observations reported here suggest bilirubin reaction with ganglioside is at least a two-step process.

\section{Speculation}

Bilirubin cytotoxicity may be related in part to plasma membrane effects which involve bilirubin interaction with ganglioside at concentrations which do not disturb mitochondrial metabolism. The difference between the ganglioside composition of infant and adult gray matter may in part explain the marked cytotoxicity of unconjugated bilirubin for the infant nervous system.

Kernicterus, a bilirubin encephalopathy, results from the accumulation of nonconjugated, non-albumin bound bilirubin which leads to well described changes in the nervous system (6). In most experiments, anoxia $(1,9,18)$, or hypoglycemia (17), in association with hyperbilirubinemia, produces more profound lesions in the experimental model $(1,9,18)$ than nonanoxic hyperbilirubinemia. Neurons in such lesions demonstrate cytoplasm with myelin figures and dense bodies thought to be a pigment-lipid complex (10). Cytoplasmic membranous bodies have been described in enlarged Purkinje cell mitochondria of Gunn rats although none were present in astrocytes or oligodendrogliocytes (19). The enhanced susceptibility of specific regions of the nervous system to bilirubin toxicity as well as the increased susceptibility of the infantile nervous tissue has not been explained adequately.

Metabolic studies suggest that bilirubin pigment exerts four effects in mitochondrial reactions: (l) stimulation or inhibition of respiration depending on concentration of bilirubin, (2) abolition of respiratory control, (3) uncoupling of oxidative phosphorylation, and (4) induction of energy-requiring swelling. Levels of total bilirubin in the range of $10-40 \mu \mathrm{mol} /$ liter increase oxygen consumption of mitochondria $(2,11)$. Concentrations necessary to initiate uncoupling of oxidative phosphorylation within adult or infant rat liver and brain mitochondria in vitro are much higher than those found in the brains of adult Gunn rats with experimental bilirubin encephalopathy $(3,5)$. Furthermore, brain mitochondria of newborn guinea pigs with the clinical features of severe bilirubin encephalopathy fail to demonstrate uncoupling of oxidative phosphorylation (4). Bilirubin inhibition of oxygen uptake is greater for whole brain homogenate from newborn rats than from adult rats (21). Mitochondria from whole brain or cerebellum of newborn guinea pigs with bilirubin encephalopathy fail to exhibit 